\title{
Advances in research on attachment-related psychotherapy processes: seven teaching points for trainees and supervisors
}

\author{
Alessandro Talia, ${ }^{1}$ Svenja Taubner, ${ }^{1}$ Madeleine Miller-Bottome ${ }^{2}$ \\ ${ }^{1}$ Institute for Psychosocial Prevention, Heidelberg University Hospital, Heidelberg, Germany; ${ }^{2}$ Department of Psychology, New School \\ for Social Research, New York, NY, USA
}

\begin{abstract}
While the rich body of attachment theory and research has inspired many psychotherapists, trainees and less experienced clinicians interested in attachment-informed work can often feel unsure about what processes are attachment-related and how to attend to them during therapy. Recent advances in attachment-informed psychotherapy research offer some practical guidance. Studies published over the last five years show that patients and therapists of different attachment classifications communicate in distinct ways during therapy sessions. In particular, Talia and his colleagues have introduced the Patient Attachment Coding System and the Therapist Attunement Scales, two measures that accurately predict patients' and therapists' Adult Attachment Interview and Reflective Functioning score based on the occurrence of distinct communication markers during therapy sessions. This paper discusses the implications of these recent studies for psychotherapy training and presents seven teaching points for supervisors and for the next generation of clinicians.
\end{abstract}

Key words: Attachment; Language; Psychotherapist; Training; Adult Attachment Interview.

\section{Introduction}

The influence of attachment theory on psychological treatments seems to be ever increasing (Slade, 2016).

Correspondence: Alessandro Talia, Institute for Psychosocial Prevention, University of Heidelberg, Bergheimer Straße, 54, Heidelberg 69915, Germany.

E-mail: alessandrotaliapsy@gmail.com

Citation: Talia, A., Taubner, S., \& Miller-Bottome, M. (2019). Advances in research on attachment-related psychotherapy processes: seven teaching points for trainees and supervisors. Research in Psychotherapy: Psychopathology, Process and Outcome, 22(3), 359368. doi: 10.4081/ripppo.2019.405

Acknowledgments: AT wishes to thank Gerry Byrne for having inspired some of the ideas contained in this paper.

Contributions: all the authors participated in defining the content of the paper. AT and MMB wrote the first draft of the paper; ST revised and edited the manuscript.

Conflict of interest: the authors declare no potential conflict of interest.

Received for publication: 14 April 2019.

Revision received: 24 October 2019.

Accepted for publication: 26 October 2019.

This work is licensed under a Creative Commons Attribution NonCommercial 4.0 License (CC BY-NC 4.0).

${ }^{\circ}$ Copyright: the Author(s), 2019

Licensee PAGEPress, Italy

Research in Psychotherapy:

Psychopathology, Process and Outcome 2019; 22:359-368

doi:10.4081/ripppo.2019.405
There is a wide array of treatment models drawing from an evidence base that emphasizes secure attachment as the building block of good mental health (Cassidy \& Shaver, 2016). Many clinicians and scholars across disciplines and theoretical orientations follow Bowlby in recognizing the transformative power of the therapeutic relationship in its parallels with an attachment bond (e.g., Eagle, 2013; Fredrickson, 2013; Johnson, 2012; Liotti, 2004). Some manualized treatments even go so far as to apply attachment theory to the development of specific therapeutic techniques (e.g., Bateman \& Fonagy, 2016). This all but universal embrace of attachment theory within the field of psychotherapy has been supported by research with the Adult Attachment Interview (AAI, Main, Kaplain, \& Cassidy, 1985), an interview that probes for autobiographical narratives about early attachment experiences. The clinicians of today have been inspired by this popular extra-clinical attachment assessment, and they are now ready for an evidence-based guide for identifying markers of attachment in psychotherapy sessions and targets for intervention.

Thanks to research with the Patient Attachment Coding System (PACS, Talia, Miller-Bottome, \& Daniel, 2017) and the Therapeutic Attunement Scales (TASc, Talia, Muzi, Lingiardi, \& Taubner, 2018), two measures of attachment developed for the psychotherapy context and validated with the AAI, the clinical applications of attachment theory can be extended to the moment-to-moment process of psychotherapy sessions. Whereas the AAI has shown that individuals represent their early relationships with their parents in distinct ways, until the introduction of the PACS and the TASc it was unclear how such differences could be observed in patients' in-session 
behavior (Eagle, 2006; Obegi \& Berant, 2009). Several clinical authors advanced hypotheses regarding how the various attachment classifications manifest in psychotherapy, often assuming that the AAI narrative features translate in therapy as transference-like attitudes and approaches to the therapy relationship (e.g., Wallin, 2007; but see Daniel, 2009 and 2011 for an alternative perspective). Evaluating and expanding on these early insights, research with the PACS and the TASc provides a method for tracking attachment differences as reflecting differences in how patients and therapists establish trust in the truth and relevance of what they communicate (which Fonagy \& Allison, 2014, call epistemic trust). These innovations can guide assessment as well as therapeutic interventions, particularly for trainees and less experienced clinicians, who may feel unsure about how to recognize and respond to attachment-related process in sessions.

This paper presents such recent research along with specific clinical implications that can contribute to the training of psychotherapists. We begin by summarizing research on how patients and therapists of different attachment classifications communicate in session. We emphasize specifically research findings with the PACS and the TASc, and we do not attempt to offer a comprehensive presentation of contemporary attachmentinformed psychotherapy research (the interested reader is referred to recent compendia such as Daniel, 2014, and Holmes \& Slade, 2017). We continue presenting a number of teaching points for therapy training and supervision based on these findings.

Specifically, we discuss how knowledge of in-session attachment markers can help trainees and their supervisors: i) construct an attachment-based case formulation; ii) develop more process-oriented clinical listening; iii) identify triggers for negative countertransference; iv) assess therapeutic impasses; v) create deliberate practice exercises; vi) increase mindfulness of one's own listening and reactivity patterns; and vii) provide new supervisory techniques and training objectives. We believe that this research can offer useful insights into areas of development for psychotherapy trainees as well as their supervisors.

The perspective on attachment-informed psychotherapy presented in this paper departs from Bowlby's emphasis on attachment as a motivational system activated by threats and distress and focuses on the broader phenomenon of the pragmatics of verbal communication and meaning-making in the therapeutic relationship. While we focus here on a relatively newly discovered dimension of interpersonal dialogue in psychotherapy, we do not mean to de-emphasize Bowlby's focus on separation and loss. This new horizon of attachment research only builds upon the wealth of work demonstrating our intrinsic drive for closeness and safety with others, as well as our reliance on others for learning about the world and making meaning of how we experience it.

\section{Attachment and communication in the clinical context}

Can we identify the attachment classifications of our patients simply by tracking how they speak in-session? The PACS was developed in an attempt to answer this very question (Talia et al., 2014). The authors of the PACS began by conducting a qualitative analysis of the transcribed sessions of a small sample of patients whose AAI classifications were obtained in advance. Through this work, they realized that patients of different attachment classifications could be distinguished according to how they used language at an interpersonal level. Patients classified as secure on the AAI engaged in a free and collaborative dialogue with the therapist and established connection with ease. Patients classified as dismissing appeared almost to be talking to themselves, providing scant cues for support, as if releasing the therapist from getting too involved. Patients classified as preoccupied seemed to enlist the therapist's constant validation of their perspective and left little room for independent contributions and separateness in the relationship.

This initial analysis led the authors of the PACS to hypothesize that attachment classifications are expressed in psychotherapy as generalized patterns for communicating one's experience. The association between these communication characteristics and the AAI was so strong that they could serve as a standalone measure of attachment, without the need for additional structured assessments. The authors of the PACS then compiled a list of items that characterized the discourse of patients with different attachment classifications, which now form the basis for coding the main scales of the PACS. The validity of this coding method was established in a large-scale study showing that the PACS independently predicts patients' pre-treatment AAI classification $(\mathrm{N}=156 ; \mathrm{k}=.82)$, in a sample of patients from three countries and including both psychodynamic and cognitive-behavioral treatments (Talia et al., 2017).

Beyond the utility of the PACS as a speedier assessment of attachment in psychotherapy research, most relevant for the focus of the current paper is that the research with this instrument has identified distinct communication markers that clinicians can learn to listen for during sessions. The PACS works by identifying the presence and frequency of fifty markers embedded within in-session discourse (for example, 5. The patient discloses distressful emotions experienced in the present; 38. The patient laughs over distress; 45 . The patient quotes past thoughts with direct discourse). The occurrence of these characteristics in a psychotherapy session transcript leads to rating a number of subscales and five main PACS scales: Proximity seeking (which rates the extent to which the patient openly expresses vulnerability); Exploring (which rates the extent to which the patient demonstrates agency and openness with regards to their positive experience); Con- 
tact maintaining (which rates the extent to which the patient communicates about the therapeutic relationship); Avoidance (which rates the patients' reluctance to describe in detail examples, attitudes, and internal experiences); Resistance (which rates the patient's lack of clarity and orderliness in the exposition). A patient is assigned one of three PACS attachment classifications (secure, dismissing, and preoccupied) and one of nine sub-classifications based on the overall configuration of these scales. While it is outside of the scope of this paper to provide a comprehensive description of the PACS (the interested reader can read more about the instrument and coding examples in Talia et al., 2017, 2019a), the following paragraphs will present a short description of three domains in which one can observe the distinguishing features of the main attachment classifications.

\section{Attachment-related differences in narrative construction}

One of the most obvious in-session differences between patients of different attachment classifications can be found in their narratives. In his seminal work, Jeremy Holmes (2001) proposed that narrative tendencies similar to those found in the AAI find expression in the stories patients share therapy. Holmes speculated that secure patients' narratives are more coherent and balanced, dismissing patients' narratives are overly succinct and unemotional, and preoccupied patients are overwhelmed by their experiences and struggle to fit them into clear stories.

Psychotherapy research on attachment-related in-session processes provides empirical support to these hypotheses. In particular, the secure classification in the PACS is associated with telling narratives that are vivid and to the point. In relaying their narratives, these patients' describe distinct physical actions in close causal succession, which makes them easier to be visually imagined by the listener. Secure patients also make it clear why they are recounting a particular story - either because the narrative serves to illustrate some previous claim, or because the narratives themselves are constructed so that the most salient information is presented at the end, like a climax to a harrowing tale or a punchline to a joke (Talia \& Miller-Bottome, 2014).

In contrast to secure patients, dismissing patients detail narratives infrequently or their narratives are exceedingly terse (Daniel, 2011) they contain more pauses (Daniel, Folke, Lunn, Gondan, \& Poulsen, 2018), and lack vividness (Talia et al., 2017). While these patients' discourse is coherent and easy to follow, it may give the impression that the speaker is not interested in receiving support or validation from the therapist. Preoccupied patients, on the other hand, may construct detailed narratives, but they often fail to make clear why they are telling a particular story. Their narratives are characterized by exaggerated one-sidedness, extended quotations of past dialogues, and incoherence and vagueness, such that contributions from the therapist seem unwelcome. The PACS has shown that these differences can be observed in any sort of narrative in psychotherapy, regardless of whether they are related to attachment or a distressful topic (Talia et al., 2017).

\section{Attachment-related differences in expressing attitudes}

Secure speakers not only recall specific memories, but they also tend to provide salient evaluations (of others, themselves, and the therapist) and express the feelings that are related to these. For example, secure patients will generally follow up a description of a hurtful treatment by a significant other by criticizing the other and mentioning how he or she made them feel. As another example, secure patients will praise the helpfulness of the therapist and elaborate by describing a feeling of closeness and gratitude (Miller-Bottome, Talia, Safran, \& Muran, 2018).

Insecure patients are distinctively different in this respect. Some of these patients criticize or praise without mentioning any feelings. They either speak in overly objective, exaggerated terms (a hallmark of some preoccupied speakers, who are classified $\mathrm{C} 1$ in the PACS and E2 in the AAI) or by downplaying the emotional effect that experiences had on them (a hallmark of some dismissing speakers, classified A2 in the PACS and Ds3 in the AAI). Other patients would mention their internal experiences and thoughts from the past without expressing an independent stance in the present, in ways that appear detached (and then classified A1 in the PACS and Ds1 in the AAI) or indecisive and confused (and then classified $\mathrm{C} 1$ in the PACS and E1 in the AAI).

\section{Attachment-related differences in perspective-taking}

Research with the PACS reveals a third aspect that is closely associated with patients' attachment classification: the capacity for mentalizing. Mentalizing is defined as the ability to understand behavior based on mental states that underlie the behavior and may serve to explain it (Allen, Fonagy, \& Bateman, 2008). Consistent with early intuitions by Fonagy and his colleagues (Fonagy, Steele, Steele, Higgitt, \& Moran, 1991), secure patients often describe their own and other people's intentions and behavior while discussing relevant beliefs and desires. They speak with candor, but do not try to enlist the listener's approval or support, as if they rest relatively assured that they will be trusted and listened to (Talia et al., 2019a). Insecure patients have difficulties in engaging in such a collaborative meaning-making process. Some of them are reluctant to make guesses about mental states, some sound too self-assured, and some are vague and difficult to understand. By failing to provide justification for how they and their significant others acted in the way they did, they limit their interlocutors' ability to understand and believe them entirely. Thus, similarly to the other attachment-related differences discussed above, differences in perspective-taking reflect differing capacities in fostering epistemic trust (Fonagy \& Allison, 2014). 


\section{Attachment-related differences in therapists}

Encouraged by the finding that patients' discourse in one session is a reliable predictor of their independently obtained AAI classification, Talia et al. (2018) more recently hypothesized that a therapist's attachment status might influence their work with their patients as well. Initially, they did not expect to find associations between therapists' in-session discourse and their AAI classification as strong as those found in work with the PACS. Therapists' work was thought to be a learned skill, with therapist attachment status only being one among many influences on therapists' behavior in-session. Nevertheless, pronounced characteristics in therapists' interventions were found to distinguish between the three main AAI classifications. The TASc was then devised to assess therapists' attachment based on any session of therapy and validated on an independent sample of fifty psychodynamic psychotherapists who had been independently assessed with the AAI.

In the TASc, the therapists are classified as secure when they make use of three characteristic types of interventions. First, they offer their own views on patients' experience in a way that is open to correction and elaboration from the patient (rated on the Self-state conjecture scale). For example, they would ask if a patient was feeling a certain emotion, or they would make a tentative conjecture about the patient's current wishes and needs. Second, they would validate patients' previously expressed experience by offering their own subjective perspective in support (rated on the Empathic validation scale). Third, they would convey their subjective experience of the patient (rated on the Joining scale). Open questions, advice, psycho-education, and repetitions of what the patient has said (i.e. clarifications) were not found to differentiate between attachment classifications.

In contrast to the therapists classified secure, the ones classified as dismissing use the markers described above only sparingly. Therapists classified as preoccupied use markers from the Empathic validation and Joining scales but not from the Self-state conjecture scale, whose characteristic tentativeness is largely absent in their interventions. Therapists with dismissing and preoccupied AAI classifications also use two additional sets of markers. The therapists with a dismissing classification seem to release themselves from offering their subjective perspective on their patients' internal experience, for example by repeating back a patient's disclosure in a downplayed form (e.g. so you're feeling a bit sad). The therapists with a preoccupied classification speak in a way that appears to restrict the possibility of the patient to correct them, for example by conveying their opinions on patients' significant others in a seemingly entitled way. These communication markers are rated on two other scales, Detaching and Coercing.

\section{Patient Attachment Coding System and Therapeutic Attunement Scales markers reflect instances of cooperative discourse}

We think it is important to note that the markers of insecure in-session attachment discovered with the PACS and the TASc do not themselves constitute alliance ruptures, negative transference enactments, or forms of resistance. Although insecure in-session markers of attachment can evoke frustration, confusion, and disconnection in therapists, their pervasiveness and stability in patients' discourse across topics from the first sessions of treatment and even in interviews outside of psychotherapy (Talia et al., 2019b) suggests that they are something the speaker alone brings to the therapeutic interaction. They should thus be regarded as independent from the speaker's experience of the interaction or even the formation of a strong personal bond. On the other hand, alliance ruptures or negative transference enactments typically involve a subjective experience of affective discord and arise from a strain in the trust in the therapist or the process (Miller-Bottome et al., 2018); such events are thus a function of the experiences and histories particular to that therapeutic dyad.

Moreover, we believe it is helpful to think of the PACS and the TASc markers as instances of cooperative discourse, rather than defensive evasions from the therapeutic relationship or the process. On closer inspection, insecure PACS markers are typically instances in which the speaker discloses their beliefs and desires, details examples to support their claims, and provides justification to their actions and plans. Despite perhaps being limited in their capacity to describe their experiences to another person, these discourse markers represent speakers' efforts at being understood and believed. This can be contrasted with ruptures, in which the patient disengages from the dialogue or blocks collaboration with the therapist by, for example, providing telegraphic responses or by denying any internal experience at all (Eubanks Carter, Muran, \& Safran, 2015b). We believe that distinguishing the insecure PACS markers from alliance ruptures may help therapists develop a richer conceptualization of the patient and increase their capacity to empathize with the patient's attempts to collaborate.

In the section that follows, each teaching point will present a re-framing or re-construal of how we conceptualize attachment in psychotherapy and the related clinical implications for therapy training.

\section{Seven teaching points for clinical training}

\section{Attachment classifications provide trainees and supervisors a diagnostic tool for case formulation}

Because of its trans-theoretical applications and its reliance on validated assessments, attachment theory is a significant resource for case formulation (Steele \& Steele, 2008). Until recently, however, attachment-informed case 
formulation has suffered a number of limitations. First of all, the previous emphasis on individual differences in attachment as transference-like perceptions and expectations tended to obscure many subtle aspects of the therapeutic interaction that are nonetheless clinically important (Eagle, 2006; Wachtel, 2010). Second, not many clinical settings allow for the administration and transcription of a structured interview, especially for clinicians who work in private practice settings, and especially if one wants to administer such interviews more than once or twice and track change. The PACS seems to combine the in-depth reach of observer-based measures while meeting the practical demands of clinicians and researchers (Talia et al., 2017).

It is probably not realistic to ask that all therapy trainees immerse themselves in learning how to code with formal attachment assessments; yet those involved in the training of clinicians must study actual attachment-related in-session communication if they want to make sure that their students' clinical work is truly attachment informed (Slade, 2016). In particular, supervisors and teachers can teach their trainees about some of the core aspects of insession attachment described by the PACS; the three domains of in-session discourse described in the previous section are a good point of departure. Drills can be designed to show students how to gauge the fundamental elements of a patient's attachment pattern and training videos can be used to test students' learning.

Attachment-informed case formulation will yield a number of indications. At the most general level, in-session attachment classifications may lead to a type of initial case formulation that identifies the patient's overall level of personality functioning, not unlike Kernberg's focus on the patient's personality organization (Kernberg, 1976), the recent assessments developed for the DSM-5 Alternative model for Personality disorders (Zimmermann, Kerber, Rek, Hopwood, \& Krueger, 2019), or assessment with the Psychodynamic Diagnostic Manual (PDM, Lingiardi \& Williams, 2015). There is a need for more studies that rigorously test the association between attachment categories and personality (e.g., Roisman, et al., 2007), on the model of what accomplished in research on the associations between personality and RF (see e.g., Katznelson, 2014). Until then, clinicians should be aware that the discourse markers used in coding secure attachment in the AAI (and in the PACS) reflect central aspects of personality functioning, including identity diffusion $v s$ integration (Blatt \& Levy, 2003; Main, Goldwyn, \& Hesse, 2002), mentalizing (Jessee, Mangelsdorf, Wong, Schoppe-Sullivan, \& Brown, 2016; Talia et al., 2019a), and capacity for intimacy and conflict resolution (MillerBottome et al., 2018).

Finally, a case formulation informed by attachment research can lead the clinician to draw a roadmap of the therapy tasks that have to be accomplished. Research with the PACS underlines that the markers used to identify se- cure attachments overlap with therapy processes that have been historically considered as necessary for any treatment to be successful: disclosing one's emotions and needs, constructing clear narratives, reflecting on the therapeutic relationship are only some examples. In this way, attachment-informed case formulation is at the same time a formulation of patients' problems in interpersonal communication and a way to identify therapeutic tasks that the therapist and the patient need to emphasize.

\section{Learning in-session markers of attachment helps clinicians develop an ear for verbatim process}

It seems to us that it is common amongst trainees to focus too much on the content of patients' communications in sessions and too little on how patients communicate. Clinicians interested in attachment-informed work can sometimes rely too heavily on inference; guessing the patients' attachment pattern solely based on the details of patients' relationships and the categories of experiences patients disclose: traumatic, pleasurable, affirming, disappointing (Wallin, 2007). For example, clinicians often misunderstand a patient's discussion of wanting to avoid contact with her husband to mean that the attachment pattern is dismissing. Without any strong support from research, many clinicians conflate the quality of the attachment experiences the patient reports with their attachment patterns. This can translate in supervision to meetings devoted to a chronicling of a patient's life history or a summation of the topics discussed by the patient at the expense of a more detailed picture of the interaction. Supervisors and trainers must keep in mind that, with no discussion of process (the sequence of dialogue, the phrasing and wording of patients' speech turns, their responses to the therapist's comments and vice versa), no assessment of patients' attachment patterns is possible.

The research discussed in this paper enables the therapist to develop a different kind of detail-orientation that extends beyond the surface of patients' communication and into the crucial differences between a patient saying I'm feeling so sad about it (a marker of secure attachment), I felt sad yesterday, but that's to be expected (a marker of dismissing attachment) and I'm so sad, it's just like 'I know you're a cheater!' (a marker of preoccupied attachment). The differences in tense, syntax, and focus in each of these remarks can be felt in the here-and-now sense of connection and collaboration with the patient. Ideally, supervisors can help their supervisees pay attention to these aspects in the transcripts or the videos of the supervisee's sessions. If recording technology is not available, supervisors armed with the PACS can focus on communication in addition to content with questions such as How did he say it - what were his exact words? or How did he reply to your intervention?. This perspective may remind the reader of perspectives on psychoanalytic technique most often associated with authors such as Schlesinger (2003), Shapiro (1965), and many others 
(e.g., Boston Change Process Study Group, 2018; Joseph, 1989; Ogden, 1977) who emphasize examining the form, function, and process of patients' communications in clinical phenomena like transference.

\section{In-session attachment markers identify triggers for common countertransference reactions and alliance ruptures}

Trainees are often beset by a strained connection or by a lack of collaboration that sometimes feel untraceable to any one remark by the patient. Recent attachment-informed psychotherapy research may be of some help in this regard. The discourse markers of the PACS suggest that patients of different attachment classifications speak in ways that differ subtly but may have a potent interpersonal impact. The way in which preoccupied patients speak may tend to engender in the therapist feelings of being overwhelmed or angry, while the way in which dismissing patients speak may engender more boredom and disinterest instead. Some studies support the idea that distinct emotional reactions in the therapist are associated with insecure attachment classifications in the patient (Daniel, Lunn, \& Poulsen, 2015; Martin, Buchheim, Berger, \& Strauss, 2007), while secure AAI classifications have been shown to be associated with more positive observed therapeutic relationships (Folke, Daniel, Poulsen, \& Lunn, 2016).

The fine-tuned ear facilitated by attending to in-session attachment markers can help the trainee identify the momentary shifts in patients' discourse that may trigger negative countertransference reactions in themselves. Thanks to these processes, the trainee can track in real time the subtle but distinct discursive acts associated with untoward reactions in the therapist: excessive quotation of discourse from past interactions, minimizing or downplaying remarks, or the insistence upon stating a thought in response to a probe about emotion, just to name a few. This application of attachment research may be invaluable. Identifying the source for such common reactions as frustration, confusion, boredom, emotional distance can help the trainee understand and thus better tolerate these internal states, often anxiety- or shame- inducing.

It is important to note that tracking such in-session discourse markers can be carried out mentally by the therapist without that he or she explicitly remarks upon them. An improved ability to trace the moment-to-moment sources of countertransference reaction may, alone, facilitate a restructuring of the therapists' internal experience; in turn, this may lead to more skillful and less reactive therapeutic interventions. We expect that such restructuring will in time help the trainee develop a greater capacity to accept patients and their suffering for what they are, along the lines of that radical acceptance that Marsha Linehan recommends to encourage in borderline patients (Linehan \& Wilks, 2015) and that Holmes and Slade (2017) have seen as lying at the heart of attachment-informed psychotherapy.

\section{Accurate assessment of in-session attachment markers can help clinicians detect and attend to ruptures with greater sensitivity}

Accurate assessment of in-session markers of attachment can help clinicians stay grounded in the face of perceived ruptures and impasses. Trainees can easily mistake insecure markers as signals that a rupture has occurred. This can lead to over-detection and reactivity to perceived ruptures, which in our observations can beget further ruptures. To avoid this, trainees must grasp a duality inherent in insecure markers: they are at once patients' way of communicating information and establishing trust in the clarity and validity of which they speak and also characteristics that may stymie mutual exploration of their internal experience. Research with the PACS and TASc suggests that these markers are not volitional or defensive reactions to the process, but constraints patients' capacity to communicate in an open and balanced way.

How can this re-construal help therapists in the moment? Therapists are often trained to go against the grain. Across different theoretical orientations, therapists are taught to attend to what appears to be a symptom or a defense and to remark upon these in a manner that encourages the patient doing something differently (Frederickson, 2013; Gray, 1990). Recent research on insession attachment suggests that a different stance is possible with respect to attachment-related markers. These markers arise every few seconds in speaking about a variety of topics, regardless of the listener, and they comprise patterns so automatic and fundamental to patients' self-expression that they are largely inaccessible to conscious awareness. Thus, therapists and supervisors who recognize these markers may choose to orient to them not as defenses to be blocked or even to be labeled and attended to, but as an intrinsic and enduring characteristic of the patient to be worked with, at least initially.

The research on the type, sequence, and frequency of interventions most effective for the different attachment classification is still in its infancy, and more specific recommendations necessitate more qualitative analyses and case studies. In the meantime, supervisors can encourage a spirit of judicious experimentation in going against one's immediate instincts and going with the patient's communication style. For example, a dismissing patient's minimal response can be interpreted not as a dismissal of the therapist, but as an invitation for the therapist to add more. A preoccupied patient's excessive or confusing replaying of past episodes or overriding of the therapist's comments may not be interpreted as an attempt to devalue or ignore, but to provide the therapist with as much information as possible.

A slightly different implication emerges for treating secure patients. Up until now, it was largely assumed that insecure patients experience alliance ruptures at a greater frequency than their secure counterparts, who were thought to experience a greater degree of trust and safety 
in the therapeutic relationship (e.g. Eames \& Roth, 2000). However, research suggests that what distinguishes secure patients is their capacity to repair ruptures when they do arise (Miller-Bottome, Talia, Eubanks, Safran, \& Muran, 2019). Secure patients may facilitate rupture repair by openly disclosing feeling anxious, angry, or distant from their therapist, reflecting on possible sources of these negative emotions, and stating their needs in present terms. Such disclosures can be commonly mis-recognized as a sign of attachment insecurity when in fact they initiate the process of repair. Supervisors informed by attachment-research can remind their supervisees that secure patients will disclose that they have experienced a rupture in a more open and collaborative fashion, and that what distinguishes secure patients from insecure patients is the ability to facilitate repair.

\section{In-session attachment markers can be used as a guide to intervention and a template for role-play and deliberate practice exercises}

While the TASc can be used, similarly to the PACS, for tracking therapeutic interventions retrospectively, it can also be used to help trainees deliver more interventions that are associated with secure attachment, that is, as a tool for attachment-informed training (Talia et al., 2018). We will suggest here two types of exercises, both of which can be practiced in pairs during awareness-focused role playing (Eubanks Carter, Muran, \& Safran, 2015a), with one trainee playing the patient and one playing the therapist. Because the markers of therapist attachment are empathic interventions that are expected to be common in any therapeutic orientation, it should be possible to practice these exercises regardless of the treatment model that the students are learning.

In the first exercise, the trainee who plays the therapist attempts to abstain from using open questions, clarifications, advice, and psycho-education, which are not linked to any one attachment classification in particular and thus do not seem to serve directly any attachment-related process. The trainee playing the therapist may also focus on practicing one particular type of secure attachment intervention (e.g., Self-state conjecture, Empathic validation, or Joining) or individual markers from any one of these scales. This exercise may help the therapist bolster his or her attention to attuning to the patient, which in ordinary circumstances may be disrupted when connecting to the patient is too challenging, emotionally or otherwise. A deliberate focus on active attunement may thus spotlight weaknesses in therapists' empathic attunement and suggest areas for practice.

In the second exercise, the trainee who plays the patient attempts to imitate the characteristic way of speaking and mannerisms of one of his or her patients (for example, as described by Nebbiosi, 2016), paying particular attention to PACS markers that appear most frequently in the patient's discourse. This exercise may help trainees de- velop greater empathy for the cooperative intentions that underlie patients' communication. At the same time, it may be helpful to compare the reactions of their colleagues playing the therapist in the role play with their own reaction as therapists, both in terms of their subjective experience and in terms of what interventions seem most helpful.

In both exercises, the supervisor may intervene especially when the parameters are violated, and encourage trainees to focus on what felt like making or receiving that particular intervention. Similarly to supervision in Alliance-Focused Training (Eubanks Carter, Muran, \& Safran, 2015a), the supervisor may encourage trainees to verbalize their feelings and intuitions in the roleplay as part of a metacommunication process. In this way, the PACS and the TASc can help supervisors and trainees to structure deliberate practice and role playing so that trainees can gradually learn to tailor their responses in a way that is informed by contemporary research on in-session attachment-related processes.

\section{Therapists' knowledge of their attachment classifications can increase self-awareness and acceptance of their contributions to the therapeutic process}

Another focus in attachment-informed supervision should be the analysis of videotapes of trainees' sessions and the insecure markers observable in the trainee's speech turns. The supervisor can then begin to attune to the experience of the trainee when they were using that particular type of communication. What were they trying to accomplish? What do they think was the experience of the patient in receiving the intervention? Similar to the previous exercises, the ultimate goal in this work is not to train the novice therapist to mimic by rote communication of secure therapists. Rather, the effort is to become more mindful of one's own communication style so that one can choose one's remarks more carefully. Being present and authentic should be prioritized on drilling security.

With time, we expect this type of work to produce a cascade of positive results. First, novice therapists will learn to listen to how they listen. What do they need from a patient in order to understand them and feel connected to them? What triggers boredom and when? What type of information do they tend to ask more of? This kind of selfmonitoring can enhance awareness and acceptance of one's own characteristics as well as a greater understanding of one's impact of the patient. In the same way as certain patterns of attachment elicit predictable responses in therapists, certain patterns of attachment in the therapist may elicit certain responses in patients. Knowing one's attachment pattern can inform of the anticipated responses one may tend to evoke. Patients may find dismissing therapist inscrutable, opaque, or detached. Preoccupied therapists may seem like omniscient experts or overwhelming. This knowledge may prepare the trainee 
for the types of rupture that are likely to arise with their patients.

Increased mindfulness aided by these attachment measures will help trainees take ownership of their own thresholds for establishing trust and understanding in dialogue with another person. From this awareness, the therapist can make interventions that are focused on helping the patient be more open and collaborative but grounded in their own contributions to the process. For example, trainees can be guided by their supervisors towards interventions such as I think I need you to get to the point because I personally tend to get lost with too much detail or The reason why I am asking all these questions is because it's my way to make sure I've understood you. Only when therapists learn to ground themselves in their own characteristic ways of listening and responding can they help their patients change theirs.

\section{Supervisors should learn about their supervisee's attachment in order to get the most out of supervision}

By obtaining information about their trainees' attachment classification, through interviews or videotape analysis with the TASc, teachers and supervisors can set learning objectives that are tailored to the specific student. This is especially important because the markers of secure attachment in therapists overlap with many core tasks of psychotherapy. Any psychotherapy technique - be it detailed inquiry, empty chair dialogue, or transference interpretation - is likely to be influenced by the attachment-related communication style of the therapist (Wrape, Callahan, Rieck, \& Watkins, 2017). As a consequence, it is likely that insecure trainees may struggle when engaging in these and other activities, and supervisors and trainers should emphasize helping their insecure students work on enhancing their active listening skills.

Another area in which differences in trainees' attachment might manifest is their narratives about their patients (patients' attachment classifications predict how patients speak about their therapist, Diamond, Clarkin, Stovall Mc-Clough, \& Levy, 2003; Talia et al., 2019b). We hypothesize that dismissing therapists will report their sessions by offering internally coherent descriptions of the core in-session dynamics, but without paying sufficient attention to details (either to what happened in session or to the exact content of patient's narratives). On the other hand, preoccupied therapists may get lost in detail, perhaps following all the minute aspects of the patient's narratives or in-session behavior, without making clear their assessment and formulation of the case.

It may thus be useful to ask from the beginning that the dismissing supervisees try to focus on reporting events in as much detail as possible - who said what to whom perhaps taking notes as copious as possible at the end of each sessions as an aid for recall; and that they focus on their emotions during the session and their present attitude (of liking or disliking the patient) as they speak. On the other hand, preoccupied therapist may benefit from being consistently asked to connect their observations to succinct formulations; they could also be asked to imagine alternative perspectives when considering their patients' mental states, and to speak as precisely as possible.

We expect that some trainees and supervisors may have reservations about discovering or sharing their attachment status. This is in part because attachment-informed psychotherapy research has sometimes pathologized insecure attachment classifications. In some psychoanalytic schools, insecure attachment in the therapists may be even seen as a sign that the trainee has not been analyzed sufficiently and perhaps indicate that admission into training programs should be discouraged.

The perspective proposed in this paper is different. As we discussed above, we do not view the communication styles related to insecure attachment as related to psychological conflict and resistance, nor do we view it as equal with a past history of trauma or adverse experiences in early family relationships. Rather, the communication patterns related to attachment are comparable to a personality trait perceptible to anyone in interaction, rather than internal interpersonal schemata.

\section{Conclusions}

This paper reviewed findings from recent research with two new measures of patient and therapist attachment in psychotherapy and outlined a set of clinical implications stemming from these findings that can contribute to the training of psychotherapists. New evidence regarding how attachment patterns manifest in the therapeutic interaction cast the construct of attachment in new light. The evidence shows that attachment is observable in therapy as distinct differences in how individuals listen and communicate in order to achieve shared understanding with another person. Insecure attachment in patients and therapists, rather than implying a pathological mistrust of closeness, is revealed as differences in the level of detail, clarity, and evidence they provide in communicating with another person. All seven teaching points described in the paper involve helping trainees become aware of their and their patients' attachment, and to work with attachment as a trait adapted for collaboration rather than a symptom or pathology to be healed.

\section{References}

Allen, J. G., Fonagy, P., \& Bateman, A. W. (2008). Mentalizing in clinical practice. Arlington, VA: American Psychiatric Publishing.

Bateman, A., \& Fonagy, P. (2016). Mentalization-based treatment for personality disorders: A practical guide. Oxford: Oxford University Press.

Blatt, S. J., \& Levy, K. N. (2003). Attachment theory, psycho- 
analysis, personality development, and psychopathology. Psychoanalytic Inquiry, 23(1), 102-150.

Boston Change Process Study Group (2018). Moving through and being moved by: embodiment in development and in the therapeutic relationship. Contemporary Psychoanalysis, 54(2), 299-321. doi: 10.1080/00107530.2018.1456841

Cassidy, J., \& Shaver, P. R. (2016). Handbook of attachment (3rd. ed.). New York, NY: Guilford Press.

Daniel, S. (2014). Adult attachment patterns in a treatment context: Relationship and narrative. London: Routledge.

Daniel, S. I. F. (2009). The developmental roots of narrative expression in therapy: Contributions from attachment theory and research. Psychotherapy: Theory, Research, Practice, Training, 46(3), 301-316. doi: 10.1037/a0016082

Daniel, S. I. F. (2011). Adult attachment insecurity and narrative processes in psychotherapy: An exploratory study. Clinical Psychology \& Psychotherapy, 18(6), 498-511. doi: 10.1002/ cpp.704

Daniel, S. I. F., Folke, S., Lunn, S., Gondan, M., \& Poulsen, S. (2018). Mind the gap: In-session silences are associated with client attachment insecurity, therapeutic alliance, and treatment outcome. Psychotherapy Research, 28(2), 203-216. doi: 10.1080/10503307.2016.1177673

Daniel, S. I. F., Lunn, S., \& Poulsen, S. (2015). Client attachment and therapist feelings in the treatment of bulimia nervosa. Psychotherapy, 52(2), 247-257. doi: 10.1037/a0038886

Diamond, D., Clarkin, J., Stovall-McClough, C., \& Levy, K. (2003). Patient-therapist attachment in the treatment of borderline personality disorder. Bulletin of Menninger Clinic, 67(3), 227-259. doi: 10.1521/bumc.67.3.227.23433

Eagle, M. N. (2006). Attachment, psychotherapy, and assessment: A commentary. Journal of Consulting and Clinical Psychology, 74(6), 1086-1097. doi: 10.1037/0022-006X.74.6.1086

Eagle, M. N. (2013). Attachment and psychoanalysis: Theory, research, and clinical implications. New York: Guilford Press.

Eames, V., \& Roth, A. (2000). Patient attachment orientation and the early working alliance-a study of patient and therapist reports of alliance quality and ruptures. Psychotherapy Research, 10, 421-434. doi: 10.1093/ptr/10.4.421

Eubanks-Carter, C., Muran, J. C., \& Safran, J. D. (2015a). Alliance-focused training. Psychotherapy, 52(2), 169-173. doi: 10.1037/a0037596

Eubanks-Carter, C., Muran, J. C., \& Safran, J. D. (2015b). Rupture Resolution Rating System (3RS). Mount Sinai-Beth Israel Brief Psychotherapy Research Program. Unpublished Manuscript. doi: 10.13140/2.1.1666.8488

Folke, S., Daniel, S. I., Poulsen, S., \& Lunn, S. (2016). Client attachment security predicts alliance in a randomized controlled trial of two psychotherapies for bulimia nervosa. Psychotherapy Research, 26(4), 459-471. doi: 10.1080/10503307. 2015.1027319

Fonagy, P., \& Allison, E. (2014). The role of mentalizing and epistemic trust in the therapeutic relationship. Psychotherapy, 51(3), 372-380. doi: 10.1037/a0036505

Fonagy, P., Steele, M., Steele, H., Moran, G. S., \& Higgitt, A. C. (1991). The capacity for understanding mental states: The reflective self in parent and child and its significance for security of attachment. Infant Mental Health Journal, 12(3), 201-218. doi: $\quad$ 10.1002/1097-0355(199123)12:3\%3C201::AIDIMHJ2280120307\%3E3.0.CO;2-7

Frederickson, J. (2013). Co-creating change: Effective dynamic therapy techniques. Kansas City, MO: Seven Leaves Press.
Gray, P. (1990). The nature of therapeutic action in psychoanalysis. Journal of the American Psychoanalytic Association, 38(4), 1083-1097. doi: 10.1177\%2F000306519003800408

Holmes, J. (2001). The search for the secure base. Attachment theory and psychotherapy. London: Brunner Routledge.

Holmes, J., \& Slade, A. (2017). Attachment in Therapeutic Practice. London: SAGE. doi: 10.1037/0033-3204.41.4.472

Jessee, A., Mangelsdorf, S. C., Wong, M. S., Schoppe-Sullivan, S. J., \& Brown, G. L. (2016). Structure of reflective functioning and adult attachment scales: overlap and distinctions. Attachment \& Human Development, 18(2), 176-187. doi: 10.1080/14616734.2015.1132240

Johnson, S. M. (2012). The practice of emotionally focused couple therapy: Creating connection. New York: Routledge.

Joseph, B. (1989). The patient who is difficult to reach. In M. Feldman \& E. B. Spillius (Eds.), Psychic equilibrium and psychic change: Selected papers of Betty Joseph (pp. 7587). London: Routledge (Original work published in 1975).

Katznelson, H. (2014). Reflective functioning: A review. Clinical psychology review, 34(2), 107-117.

Kernberg, O. F. (1976). Object relations theory and clinical psychoanalysis. New York, NY: Jason Aronson.

Linehan, M. M., \& Wilks, C. R. (2015). The course and evolution of dialectical behavior therapy. American Journal of Psychotherapy, 69(2), 97-110. doi: 10.1176/appi.psychotherapy.2015.69.2.97

Lingiardi, V., \& McWilliams, N. (2015). The psychodynamic diagnostic manual. 2nd ed. (PDM-2). World Psychiatry, 14(2), 237-239. doi: 10.1002\%2Fwps. 20233

Liotti, G. (2004). Trauma, dissociation, and disorganized attachment: Three strands of a single braid. Psychotherapy: Theory, Research, Practice, Training, 41(4), 472-486.

Main, M., Goldwyn, R., \& Hesse, E. (2002). Adult attachment scoring and classification systems, Version 7.1. Unpublished manuscript, University of California at Berkeley.

Main, M., Kaplan, N., \& Cassidy, J. (1985). Security in infancy, childhood, and adulthood: A move to the level of representation. Monographs of the Society for Research in Child Development, 50(1-2), 66-104. doi: 10.2307/3333827

Martin, A., Buchheim, A., Berger, U., \& Strauss, B. (2007). The impact of attachment organization on potential countertransference reactions. Psychotherapy Research, 17(1), 46-58. doi: 10.1080/10503300500485565

Miller-Bottome, M., Talia, A., Eubanks, C., Safran, J. D., \& Muran, J. C. (2019). Secure in-session attachment predicts Rupture Resolution: Negotiating a secure base. Psychoanalytic Psychology, 36(2), 132-138. doi: 10.1037/pap0000232

Miller-Bottome, M., Talia, A., Safran, J. D., \& Muran, J. C. (2018). Resolving alliance ruptures from an attachment-informed perspective. Psychoanalytic Psychology, 35(2), 175183. doi: $10.1037 /$ pap0000152

Nebbiosi, G. (2016). The smell of paper: On the usefulness of musical thought in psychoanalytic practice. Psychoanalytic Dialogues, 26(1), 1-9.

Obegi, J. H., \& Berant, E. (Eds). (2009). Attachment theory and research in clinical work with adults. New York, NY: Guilford Press.

Ogden, T. (1977). Projective identification and psychotherapeutic technique. London: Routledge.

Roisman, G. I., Holland, A., Fortuna, K., Fraley, R. C., Clausell, E., \& Clarke, A. (2007). The Adult Attachment Interview and self-reports of attachment style: An empirical rapproche- 
ment. Journal of personality and social psychology, 92(4), 678.

Schlesinger, H. J. (2003). The texture of treatment: On the matter of psychoanalytic technique. Hillsdale, NJ: The Analytic Press.

Shapiro, D. (1965). Neurotic Styles. Oxford, England: Basic Books.

Slade, A. (2016). The implications of attachment theory and research for adult psychotherapy research and practice. In J. Cassidy \& P. R. Shaver (Eds.), Handbook of attachment (3rd ed.). New York, NY: Guilford Press.

Steele, H., \& Steele, M. (Eds.). (2008). Clinical applications of the Adult Attachment Interview. New York: Guilford Press.

Talia, A., Daniel, S. I. F., Miller-Bottome, M., Brambilla, D., Miccoli, D., Safran, J. D., \& Lingiardi, V. (2014). AAI predicts patients' in-session interpersonal behavior and discourse: a move to the level of the relation for attachment-informed psychotherapy research. Attachment \& Human Development, 16(2), 192-209. doi:10.1080/ 14616734.2013.859161

Talia, A., \& Miller-Bottome, M. (2014). Patient Attachment Coding System 2.0. Unpublished manuscript. Institute of Psychosocial Prevention, Heidelberg University, Germany.

Talia, A., Miller-Bottome, M., \& Daniel, S. I. F. (2017). Assessing attachment in psychotherapy: validation of the patient attachment coding system (PACS). Clinical Psychology \& Psychotherapy, 24(1), 149-161. doi:10.1002/cpp.1990

Talia, A., Miller-Bottome, M., Katznelson, H., Pedersen, S. H., Steele, H., Schröder, P., ... Lingiardi, V. (2019a). Mentalizing in the presence of another: Measuring reflective functioning and attachment in the therapy process. Psychotherapy Research, 29(5), 652-665. doi:10.1080/10503307.2017. 1417651

Talia, A., Miller-Bottome, M., Wyner, R., Lilliengren, P., \& Bate, J. (2019b). Patients' Adult Attachment Interview classification and their experience of the therapeutic relationship: are they associated? Research in Psychotherapy: Psychopathology, Process and Outcome, 22(2), 174-187. doi: 10.4081/ripppo.2019.361

Talia, A., Muzi, L., Lingiardi, V., \& Taubner, S. (2018). How to be a secure base: Therapists' attachment representations and their link to attunement in psychotherapy. Attachment \& Human Development. Advance online publication. doi: 10.1080/14616734.2018.1534247

Wachtel, P. L. (2010). One-person and two-person conceptions of attachment and their implications for psychoanalytic thought. The International Journal of Psychoanalysis, 91(3), 561-581.

Wallin, D. (2007). Attachment and psychotherapy. New York, NY: Guilford Press.

Wrape, E. R., Callahan, J. L., Rieck, T., \& Watkins Jr, C. E. (2017). Attachment theory within clinical supervision: Application of the conceptual to the empirical. Psychoanalytic Psychotherapy, 31(1), 37-54. doi: 10.1080/02668734.2016. 1261927

Zimmermann, J., Kerber, A., Rek, K., Hopwood, C. J., \& Krueger, R. F. (2019). A brief but comprehensive review of research on the Alternative DSM-5 Model for Personality Disorders. Current Psychiatry Reports, 21-92. doi: 10.1007/s11920-019-1079-Z 